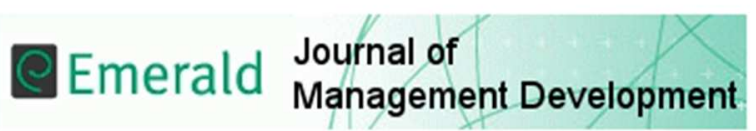

\section{Organizational factors and process capabilities in a KM strategy: Toward a unified theory}

\begin{tabular}{|r|l|}
\hline Journal: & Journal of Management Development \\
\hline Manuscript ID & JMD-04-2016-0057.R1 \\
\hline Manuscript Type: & Original Article \\
\hline Keywords: & $\begin{array}{l}\text { Organizational Culture, Organizational structure, Transformational } \\
\text { Leadership, technology utilization, knowledge management activities }\end{array}$ \\
\hline \multicolumn{2}{|l}{} \\
\hline
\end{tabular}

SCHOLARONE

Manuscripts 


\title{
Organizational factors and process capabilities in a KM strategy: Toward a unified theory
}

\begin{abstract}
Purpose- This study aims to examine the role of knowledge management (KM) enablers on KM activities in the context of Malaysian small and medium-sized enterprises (SMEs). The effects of organizational culture, transformational leadership, organizational structure, and technology utilization as infrastructural $\mathrm{KM}$ enablers are examined on $\mathrm{KM}$ activities as knowledge acquisition, knowledge conversion, application, and protection.
\end{abstract}

Design/methodology/approach- A total of 227 responses from SMEs' top management are used to assess the measurement and structural models applying partial least squares-structural equation modelling (PLS-SEM).

Findings- The results show that technology utilization and organizational structure are two main factors in KM activities (all structural relationships are supported). Surprisingly, organizational culture is only associated with knowledge conversion and protection and the findings indicate no relationships between organizational culture and knowledge acquisition and application. The results also indicate a positive relationship between transformational leadership and knowledge acquisition and the hypotheses on the association between transformational leadership and knowledge conversion, application, and protection are rejected.

Practical implications- The results of importance-performance map analysis (IPMA) imply that technology utilization has the highest importance on knowledge acquisition, conversion, and protection while organizational structure has the highest importance on knowledge application. The results of IPMA also show that organizational culture has the highest performance on all KM activities.

Originality/value- This study is amongst the few that examines the structural relationships between organizational factors and KM activities in a SME context.

Key words: Organizational culture, organizational structure, transformational leadership, technology utilization, and knowledge management activities. 


\section{Introduction}

The field of KM, its processes and activities has attracted profound interest among scholars (Silver, 2000). "Knowledge cannot be managed, only enabled” (von Krogh, 2012, p. 154). In this turbulent market, knowledge-based activities are indispensable for developing sustainable competitive advantage (Tiwana, 2002) and companies need to care more about the management of their knowledge workers (Jafari et al., 2013). A long lasting core competency is resorted to an affective KM that is facilitated by infrastructural capability (organizational factors) and process capability (KM activities) (Chan and Chao, 2008). Issues related to KM are multi-dimensional and need a holistic approach (Ale et al., 2014). Therefore, a comprehensive and integrated KM model that addresses the role of organizational factors in KM activities is crucial. Few researches study KM in SMEs (Dwivedi et al., 2011) and most KM studies in SMEs are case studies that have a brief summary of particular KM solutions (Dotsika and Keith, 2013). In this research, however, we argue that organizational factors namely, organizational culture, transformational leadership, organizational structure, and technology utilization have vital role in KM activities, and the main question addressed in this research is: 1) to what extent organizational factors impact on KM activities? 2) Which organizational factor/s has the highest importance on KM activities?

The management information system development agenda in most SMEs fail to pay proper attention to combine KM as part of the plan (Lee and Lan, 2011). This failure can be due to the budget limitations, lack of awareness among managers (Dotsika and Keith, 2013), lack of perception about processes engaged in KM, and lack of understanding the intricacy and several types of knowledge (Lee and Lan, 2011). Implementing KM initiatives in SMEs is critical, as the main resource in these companies is knowledge (Dotsika and Keith, 2013). KM success factors need to be appraised so that "decisions can be made on what to continue, what to improve, and what to discard" (Lee and Wong, 2015, p. 711). SMEs still fail to become fully aware of benefits of KM (Chan and Chao, 2008) and the associated organizational factors that bolster a KM intensive environment. 
KM in large organizations and SMEs is different (Janet and Alton, 2013) and it needs to be studied separately without applying the models in large organizations directly to SMEs. There are several conceptual and review studies about the critical success factors that may impact or hinder KM in organizations but few empirical researches were conducted. For instance, based on a review on KM in organizations, Wong (2005, p. 266) postulated 11 critical success factors in SMEs that may impact on KM, namely "management support, culture, information technology, strategy and purpose, measurement, resources, motivational aids, process and activities, organizational infrastructure, human resource management, and training and education". Migdadi (2009) attempted to examine these 11 factors on KM performance outcomes such as employee development, good external relationship, systematic knowledge activities, customer satisfaction, and organizational success. Moreover, previous studies mainly focused on the performance of KM in SMEs through comparing the descriptive results between countries (for example, Chan and Chao, 2008, Lee and Lan, 2011) or developing KM performance models (Lee and Wong, 2015) and the literature is scarce in examining the structural relationships between organizational factors and KM activities in SMEs. Therefore, the main purpose of this study is to find out the extent to which the organizational factors impact on KM activities, if any.

In addition, according to Malaysia's $10^{\text {th }}$ plan (Economic Planning Unit, 2010), so-called "knowledge SMEs" have a substantial role to play in the innovation process among Malaysian companies. SMEs make a profound contribution to manufacturing, and in developing economies they comprise 90 to 95 percent of all industrial enterprises (Loecher, 2000). Malaysia is a developing country that considers SMEs as the drivers of innovations. Malaysia has ambitious plans regarding SMEs and the role of SMEs in economic growth is clearly stated in the 2020 plan. However, understanding the way they view and practice KM brings value to South-East Asia region.

This paper is structured as follows: section 2 provides the relevant literature on organizational factors and KM processes to develop the hypotheses. Section 3, as the research method, explains the steps in data collection and several priori statistical tests are applied ensuring that the data is ready for SEM analysis. Section 4 summarizes the results of measurement model, structural model, and IPMA. Discussion, implications, and future directions are addressed in sections 5 and 6 . 


\section{Literature review and hypothesis development \\ Role of organizational culture in KM}

Zheng et al. (2010) included organizational culture as a factor participating to KM effectiveness. Even though Wong (2005) proposed that culture may be a critical success factor in KM, he did not indicate what aspects of KM are influenced by core beliefs, norms and values of SMEs. Gregory et al. (2009) found a positive relationship between group culture and employee satisfaction. Hogan and Coote (2014) studied layers of organizational culture in terms of values, artefacts, behaviour and norms and they attempted to link these substructures of culture to innovation and organizational performance. They found that values supporting information influence norms for innovation. According to Beijerse (2000), a motivating culture fits KM which is an informal culture and is characterized by an open attitude. Hogan and Coote (2014) concluded that organizational culture is positively associated with innovation and performance of firms. Lemon and Sahota (2004) regarded organizational culture as a primary determinant of innovative capabilities. Surveying 301 organizations, Zheng et al. (2010) found that culture is positively related to KM and organizational effectiveness. The findings of Lee and Choi (2003) show that culture is positively associated with socialization process. Finally, it is hypothesized that:

H1: There is a positive relationship between organizational culture and H1a: Knowledge acquisition; H1b: Knowledge conversion; H1c: Knowledge application; H1d: Knowledge protection.

\section{Role of transformational leadership in KM}

The role of leadership has moved from a traditional and command-based model to a freer and more open style of management (Nguyen and Mohamed, 2011). Transformational leaders are those that motivate and inspire their followers and empower them in the process of decisionmaking. Crawford and Strohkirch (2002) claim that transformational leadership promotes knowledge creation. In addition, Martín-de Castro et al. (2011) and Politis (2001) state that this 
type of leadership is more related to knowledge processes than transactional leadership style. Surprisingly, the results of the previous studies conducted by Nguyen and Mohamed (2011) and Analoui et al. (2012) imply that both transactional and transformational leadership styles are positively associated with KM activities. Therefore, even though research shows the negative relationship of transactional leadership on knowledge acquisition attributes (Politis, 2002), the literature still is not consistent on which leadership style is conducive to KM activities and this signals for more research cross-culturally.

Drawing on a sample of 1046 graduate students, Crawford (2005) finds a positive relationship between transformational leadership and KM behavior. Using a sample of 432 Korean organizations, Hoon Song et al. (2012) finds that there is a positive relationship between transformational leadership and organizational knowledge creation. Surveying 157 Australian SMEs, Nguyen and Mohamed (2011) indicate that transformational leadership is positively associated with knowledge exchange, socialization, and internalization. The results of study conducted by Podsakoff et al. (1990) indicate that there is no direct relationship between transformational leadership and organizational citizenship behavior. Further investigation is required on the consequences of transformational leadership within organizations and the extent to which it may impact all KM activities. Therefore, following hypotheses are developed examining the positive role of transformational leadership on KM activities:

H2: There is a positive relationship between transformational leadership and H2a: Knowledge acquisition; H2b: Knowledge conversion; H2c: Knowledge application; H2d: Knowledge protection.

\section{Role of organizational structure in KM}

According to Beijerse (2000, p. 168), a facilitating structure is critical for "the development, the acquisition, and the locking of the knowledge". Willem and Buelens (2009) found that organizational structure dimensions such as coordination and specialization positively influence knowledge sharing within organizations. They also found unexpected relationships of centralization and formalization on knowledge sharing as well. Therefore, research on the consequences of organizational structure is still ambiguous and it should be studied cross 
culturally and with scrutiny. In addition, Chen et al. (2010) studied the interaction effects of organizational structure and climate on the relationship between KM and innovativeness of Taiwanese firms. They found that the effect of KM on firms' innovativeness is positively moderated by less formalized, decentralized, and integrated organizational structure. The results of the study by Chen et al. (2010) also indicated that a decentralized, integrated, and less formalized organizational structure is positively associated with enhanced KM activities. Surveying Chinese electronics manufacturing companies, Daugherty et al. (2011) found positive relationships between formalization, decentralization, and firm's logistics service innovation capability. Their findings also suggest that specialization is not conducive to logistics service innovation capability. Wong (2005) also indicated that organizational infrastructure may have positive impact on KM in SMEs. The results of study conducted by Lee and Choi (2003) showed that a centralized organizational structure is negatively associated with knowledge creation. Zheng et al. (2010) also found a negative relationship between organizational structure and KM and organizational effectiveness. Therefore, few researches were conducted in examining the structural relationship of lean organizational structure and $\mathrm{KM}$ activities. Accordingly, it is hypothesized that:

H3: There is a positive relationship between lean organizational structure and H3a: Knowledge acquisition; H3b: Knowledge conversion; H3c: Knowledge application; H3d: Knowledge protection.

\section{Role of technology utilization in KM}

According to organizational knowledge creation theory (Nonaka et al., 2006), technology is another enabling factor that provides knowledge base and that taps on the explicit knowledge in the company. Organizational knowledge creation theory proposes the positive relationship between technology utilization and innovative capabilities. Valaei et al. (2013) hypothesize a positive relationship between technology utilization and knowledge quality of firms. The results of the study conducted by Valaei and Rezaei (2016) showed that Web 2.0 utilization is positively associated with intrinsic knowledge quality and actionable knowledge quality. Koellinger (2008) found a positive relationship between technology investment, adoption, and process, 
product/service innovation. Lee and Choi (2003) found a positive relationship between IT support and knowledge creation. It is noteworthy to understand what KM activities are influenced by technology utilization. Figure 1 schematically shows that theoretical model of the study. Finally, it is hypothesized that:

H4: There is a positive relationship between technology utilization and H4a: Knowledge acquisition; H4b: Knowledge conversion; H4c: Knowledge application; H4d: Knowledge protection.

Figure 1: Theoretical framework (Insert here)

\section{Methodology}

Malaysian SMEs from both manufacturing and service sectors were surveyed and data were collected from chief executive officers, managers and other executives of SMEs. The online questionnaire were designed through Google Docs and it was emailed to a random list of SMEs obtained from the governmental SMECORP website. The survey was emailed to 1677 SMEs. According to Sekaran and Bougie (2010), the response rate using online survey is low. For instance, online response rate is $33.3 \%$ (Watt et al., 2002) and the overall response rate for online survey is $30 \%$ (Sekaran and Bougie, 2010). To maximize the response rate of online surveys, a token financial incentive or telephone follow-up could be useful (Dillman et al., 2014). This study used telephone top-up credit to increase the response rate. After respondents filled up the survey, they could provide the code, time, and date of submitting the online questionnaire form. After confirming that the questionnaire was filled, the researcher provided the prepaid telephone top-up PIN code through email to the respondent. A number of 242 responses were received (14.4\% response rate) and 15 responses were discarded due to high missing values (more than $50 \%$ ). Table 1 shows the demographic information of the participants. The items of the KM activities, organizational structure, organizational culture, and technology utilization (shown in Appendix A) were adopted from (Chan and Chao, 2008, Lee and Lan, 2011) and the items of transformational leadership were adopted from (Avolio et al., 1999). 
Table 1: Sample characteristics $(N=227)$ (Insert here)

In addition, no matter what method is applied, refusing to acknowledge the primary rules of sampling theory produces meaningless results (Hair et al., 2013b). According to Hair et al. (2013a), before applying SEM, the sample size criterion should be determined through power analysis. This study uses a-priori sample size calculator for SEM (Soper, 2015). This calculator requires input data such as the anticipated effect size, statistical power levels, the number of observed variables (all the measurement items/indicators) and latent variables (both endogenous and exogenous constructs) in the model, and the desired probability to detect the minimum sample size for SEM technique (Cohen, 2013, Westland, 2010). Inputting the required information such as $95 \%$ desired statistical power level, 8 constructs of this study, 38 indicators (observed variables), 0.05 probability level, as well as anticipated high effect size of 0.5 , medium effect size of 0.35 , and small effect size of 0.12 , the required number of sample size is 91,91 , and 181 for each effect size respectively. Since the sample size of this study is 227 , this requirement is met as well.

\subsection{Partial least square (PLS) path modeling approach}

PLS path modeling as a variance based structural equation modeling (VB-SEM) (Lohmöller, 1989, Wold, 1975) is well-known method in the second generation of multivariate data analysis (Ringle et al., 2012). PLS approach is one of the proper approaches to examine SEM mode of analysis and it has an appropriate way of analyzing conceptual frameworks with more than one dependent variable (Hair et al., 2013a, Hair et al., 2011, Valaei et al., 2016, Rezaei et al., 2016). In addition, PLS-SEM is a well-established technique for estimating path coefficients in causal models (Birkinshaw et al., 1995). Further, PLS is a rich method for research in management and strategy fields of study (Hair et al., 2013b) and this technique is an appropriate approach for developing and testing the existing theories (Fernandes, 2012). PLS is a good technique for exploring the theoretical relation between variables (Chin and Newsted, 1999, Reinartz et al., 2009, Henseler, 2010, Hair et al., 2011, Goodheu, 2012, Fernandes, 2012, Valaei et al., 2016) 
and since the theoretical model of this study has four dependent variables, the number of causal relationships are high (16 paths) (Ringle et al., 2012), the model is complex and latent variable scores are needed for subsequent analysis (mainly importance-performance map analysis) (Hair et al., 2013a), PLS-SEM approach is preferred.

Another purpose of using of PLS-SEM is its predictive advantages such as $\mathrm{R}^{2}$ values and $\mathrm{Q}^{2}$ values of predictive relevancy (Hair et al., 2013b, Ringle et al., 2012). One of the objectives of this study is to find out to what extent organizational factors predict KM activities. In addition, this study adopted and adapted the measurement items from previous researches (shown in Appendix A), which applied reflective mode of measurements. The measurement model of this study is reflective because "the causal priority is from the constructs to the indicators, the constructs are traits explaining the indicators, the indicators represent consequences, the items are mutually interchangeable, and all items will change if the assessment of the trait changes" (Hair et al., 2013a, p. 64). Finally, SmartPLS version 3.2.4 is used to assess the measurement and structural models of the study.

\section{Results}

\subsection{Construct validity and reliability}

To test the reliability of measurement model, both composite reliability and Cronbach's Alpha values are examined. All values of factor loadings, composite reliability, Cronbach's Alpha, are shown in Table 2. Composite reliability and Cronbach's Alpha values are acceptable (more than 0.7), which ensures the reliability. There is no multi-collinearity and all indicators have variance inflation factor below 5 .

Table 2: Construct reliability and validity (Insert here)

In addition, acceptable value of average variance extracted (AVE) shows that the questionnaire is valid. Tables 3 and 4 show the discriminant validity criteria according to Fornell-Larcker criterion and heterotrait-monotrait ratio. In Table 3, the off-diagonal values are 
the correlations between the latent constructs and diagonal are square values of AVEs showing AVEs on its own construct are higher than all of its loadings with other constructs. Additionally, the results of loadings and cross-loadings showed that an indicator's loading on its own construct is higher than all of its cross loadings with other constructs. The critical value for heterotraitmonotrait ratio is below 0.9 (Teo et al., 2008). Shown in Table 4, all values are below the threshold.

Table 3: Discriminant validity - Fornell-Larcker criterion (Insert here)

Table 4: Discriminant validity - Heterotrait-Monotrait Ratio (Insert here)

\subsection{Structural model}

The R-Square values of knowledge acquisition, conversion, application, and protection (shown in Appendix B) indicate that $46.4 \%, 60.8 \%, 71.6 \%$, and $61.1 \%$ of changes in these constructs can be predicted through organizational factors. Another assessment of predictive accuracy of a model is its predictive relevance of $Q^{2}$ values (Geisser, 1974, Stone, 1974) and they are extracted through blindfolding in PLS-SEM (Hair et al., 2013a). According to Hair et al. (2013a), a $\mathrm{Q}^{2}$ value of higher than 0 as a good indicator of a path model's predictive relevancy. The $\mathrm{Q}^{2}$ results of knowledge acquisition (0.34), conversion (0.42), application (0.54), and protection (0.48) indicate that all exogenous constructs of this study have predictive relevancy with large effect sizes. In addition to R-square values, the changes in R-square when exogenous construct/s are excluded from the model ( $f^{2}$ effect size) are important as well. Likewise to $f^{2}$ effect size, the relative impact of predictive relevance $\left(\mathrm{Q}^{2}\right)$ can be assessed through $q^{2}$ effect size. The results of blindfolding procedure showed that organizational structure and technology utilization have the highest effect sizes for $f^{2}$ and $q^{2}$ effect sizes.

The results of hypotheses testing are tabulated in Table 5. All hypotheses except H1a, $\mathrm{H} 1 \mathrm{c}, \mathrm{H} 2 \mathrm{~b}, \mathrm{H} 2 \mathrm{c}$, and $\mathrm{H} 2 \mathrm{~d}$ were supported. Hypothesis $1 \mathrm{~b}$ proposes a positive relationship between organizational culture and knowledge acquisition with path coefficient of 0.138 , standard error of 0.063 and t-value of 2.202 and Hypothesis 1d poses a positive relationship between organizational culture and knowledge protection with path coefficient of 0.138 , standard 
error of 0.081 and t-value of 1.709 were supported (with $10 \%$ probability). Surprisingly, the relationship between organizational culture and knowledge acquisition (H1a) and knowledge conversion (H1c) was rejected. Perhaps, low level of trust and unclear vision and objectives may hinder acquiring and applying new knowledge and experience about stakeholders. In addition, lack of support and training to increase employees' work efficiency may also create difficulties for acquiring and exchanging the knowledge for solving new problems and improving work effectiveness and fine-tuning strategic vision. Therefore, companies should consider more about motivating (Beijerse, 2000) and knowledge friendly organizational culture (Valaei et al., 2013) that support KM activities.

Hypothesis 2a was also supported and there is a positive relationship between transformational leadership and knowledge acquisition (with 10\% probability). Perhaps, top management's support, inspiration, and enthusiastic way of conduct only provides freedom (Nguyen and Mohamed, 2011) for acquiring the new knowledge and experience (Crawford and Strohkirch, 2002) and this style of leadership seems irrelevant to the way employees convert, apply and protect the organizational knowledge and it is likely that the other style of leadership (transactional leadership) is relevant to SMEs (Analoui et al., 2012). Furthermore, all hypotheses on the relationship between organizational structure and knowledge acquisition (H3a with 10\% probability), knowledge conversion ( $\mathrm{H} 3 \mathrm{~b})$, knowledge application (H3c), and knowledge protection $(\mathrm{H} 3 \mathrm{~d})$ were supported. Finally, hypotheses on the relationship between technology utilization and knowledge acquisition (H4a), knowledge conversion (H4b), knowledge application (H4c), and knowledge protection (H4d) were also supported. This signals the importance of organizational structure and technology utilization in KM activities.

\subsection{Goodness of fit in PLS-SEM}

Hair et al. (2014) introduce standardized root mean square residual (SRMR) as a goodness of fit measure in PLS-SEM. According to them, SRMR transforms both the sample covariance matrix and the predicted covariance matrix into the correlation matrix. SRMR is the difference between the observed correlation and the prediction correlation. A value less than 0.1 (Hair et al., 2014) or 0.08, a more conservative view (Hu and Bentler, 1998), is a good fit for SRMR. Since the 
structural model of this study only has reflective constructs, the SRMR result for common factor model is relevant (Hair et al., 2014). Using the PLS-SEM as well as bootstrapping results, the results indicate a significant value of SRMR, 0.054 (T-value $=8.780)$, which is less than 0.08 . Therefore, the proposed model has a good fit.

Table 5: Structural relationships and hypothesis testing (Insert here)

\subsection{Importance-Performance Map Analysis (IPMA)}

To address the second question, we apply IPMA to examine what organizational factor/s have the highest importance and performance on KM activities. The PLS-SEM method is especially beneficial when the research focus is on the analysis of a particular construct's key sources of explanation (Ringle and Sarstedt, 2016) such as KM activities. IPMA can also help mangers and decision makers to prioritize their actions (Hair et al., 2013a). For instance, taking the knowledge acquisition as the endogenous target variable, IPMA calculates the total effects of structural model (importance) with the average values of the latent variable scores (performance) to show the important areas for the betterment of management activities. The results can show the determinants with high importance (those constructs that have a strong total effect), but also have a relatively low performance (low average latent variable scores) (Ringle and Sarstedt, 2016). Table 6 shows the results of IPMA for four main target constructs of this study i.e., knowledge acquisition, conversion, application, and protection. For example, according to Table 6, technology utilization (0.422) and organizational structure (0.182) has the highest importance and organizational culture has the highest performance on the knowledge acquisition construct (see Appendix C). Focusing on the lower right area of the IPMA shown in Appendix C, technology utilization has a high importance for the knowledge acquisition target construct, but shows a low performance compared to the other constructs. Therefore, there is an especially high potential to boost the performance of the technology utilization, which is relevant for managerial actions. Such improvements could be providing the SMEs with IT platforms that support knowledge sharing, providing communications channels across SMEs to facilitate knowledge sharing between them, or investments in effective KM technologies to enable knowledge sharing between employees. 
Taking knowledge conversion as the target construct, technology utilization (0.425) and organizational structure $(0.207)$ has the highest importance and organizational culture has the highest performance on the knowledge conversion construct (see Appendix D). Therefore, there is substantial room for improvement, making the aspects underlying technology utilization construct extremely relevant for managerial actions.

Considering knowledge application as the target construct, organizational structure (0.674) and technology utilization (0.280) has the highest importance and organizational culture has the highest performance on the knowledge application construct (see Appendix E). Emphasizing on the lower right area of the IPMA shown in Appendix E, organizational structure has a high importance for the knowledge application target construct, but shows a low performance compared to the other constructs. Therefore, there is an especially high potential to improve the performance of the organizational structure, which is relevant for managerial actions. The improvements could be designing processes that facilitate knowledge exchange across business functions, promoting collaborative rather than individualistic working behavior, possessing a system that captures both failed and successful experiences, having a common knowledge platform that provides employees with work-related assistance, and having high "reuse rate" of important knowledge. Finally, knowledge protection as the target construct, technology utilization (0.412) and organizational structure (0.409) has the highest importance and organizational culture has the highest performance on the knowledge protection construct (see Appendix F). However, as mentioned above, there is substantial room for improvement, making the aspects underlying organizational structure construct particularly relevant for managerial actions.

Table 6: IPMA results (Insert here)

\section{Discussion and conclusion}

This study developed a unified model of organizational factors and KM activities in SME context and it also provided evidence on the structural relationships between organizational factors i.e., organizational culture, transformational leadership, organizational structure, and 
technology utilization and KM activities i.e., knowledge acquisition, conversion, application, and protection. Addressing the first research question, our study found that all organizational factors are partially (organizational culture and transformational leadership) and totally (organizational structure and technology utilization) relevant to KM activities. The results showed that $46.4 \%$ of changes in knowledge acquisition, $60.8 \%$ of changes in knowledge conversion, $71.6 \%$ of changes in knowledge application, and $61.1 \%$ of changes in knowledge protection could be predicted through organizational factors. The findings suggest that in SME setting, the most significant organizational factors to $\mathrm{KM}$ activities are organizational structure and technology utilization. Therefore, it can be concluded that the more SMEs ponder on their lean and decentralized organizational structure as well as applying various technologies, the higher they will experience KM activities.

This study offers several theoretical implications. Given the sparseness of research on the role of KM in SMEs (Dwivedi et al., 2011), this research contributes to the literature by investigating organizational factors that enable KM activities in SMEs. Previous research on the KM critical success factors in SMEs (Migdadi, 2009, Wong, 2005) failed to indicate what are the effects of their proposed factors on each KM activity. Even though Migdadi (2009) tried to examine the role of KM critical success factors on systematic knowledge activities, the flaws of his study were 1) considering systematic knowledge activities as a single obscure construct, and 2) not indicating which aspects of KM activities were influenced. But, this study had a rigorous examination to the concepts of KM activities.

Similar to previous studies (Zheng et al., 2010, Lee and Choi, 2003) and showing the importance of culture in $\mathrm{KM}$, the findings indicate that organizational culture is conducive to knowledge conversion and protection. In line with (Hoon Song et al., 2012, Martín-de Castro et al., 2011, Politis, 2001, Nguyen and Mohamed, 2011), the results also highlighted the significance of transformational leadership in KM. Transformational leadership was found as a significant factor to merely the knowledge acquisition and interestingly it was not relevant to other KM activities. Perhaps, this is due to lack of timely communications and knowledge sharing between top management and employees or chances are that transactional leadership style is relevant to KM activities as stated by Analoui et al. (2012). In contrast with Zheng et al. (2010) who found a negative relationship between organizational structure and KM, our results 
imply a positive relationship between organizational structure and all KM activities, which is in agreement with (Daugherty et al., 2011, Chen et al., 2010). Similar with Lee and Choi (2003), Nonaka et al. (2006), Valaei et al. (2013) and Valaei and Rezaei (2016), this study found that technology utilization is the most significant factor which is imperative to KM activities.

\section{Managerial implications and future direction}

From a practical point of view, due to the existence of Malay, Chinese, and Indian ethnic groups in Malaysia, the results of this study can also be applied to SMEs in other South-Asian countries. Our study suggests that managers should be aware of the organizational factors that play a significant role in KM activities. SMEs' managers and owners can prioritize their managerial actions based on the results of IPMA. IPMA addresses the important areas for the improvement of management activities. Technology utilization and organizational structure has the highest importance on the knowledge acquisition, conversion, application, and protection constructs. In other words, managers should note that one point increase in the performance of technology utilization and organizational structure is expected to increase the performance of knowledge acquisition, conversion, application, and protection by the value of total effect. Organizational culture has the highest performance on KM activities' constructs.

Since KM in large organizations and SMEs is different (Janet and Alton, 2013) and it needs to be studied separately, further investigation is required to examine other organizational factors. Empirical studies on organizational factors and KM activities in SME context are scarce and factors influencing them need to be studied with scrutiny. Future research should investigate the impact of other organizational factors such as strategy (Lee and Wong, 2015), functional diversity, and organizational memory on KM activities.

Appendix A: Measurement items

Appendix B: PLS results

Appendix C: IPMA for knowledge acquisition

Appendix D: IPMA for knowledge conversion

Appendix E: IPMA for knowledge application 


\section{Appendix F: IPMA for knowledge protection}

\section{References}

Ale, M. A., Toledo, C. M., Chiotti, O. and Galli, M. R. (2014), "A conceptual model and technological support for organizational knowledge management", Science of Computer Programming, Vol. 95, Part 1, pp. 73-92.

Analoui, B. D., Doloriert, C. H. and Sambrook, S. (2012), "Leadership and knowledge management in UK ICT organisations", Journal of Management Development, Vol. 32 No. 1, pp. 4-17.

Avolio, B. J., Bass, B. M. and Jung, D. I. (1999), "Re - examining the components of transformational and transactional leadership using the Multifactor Leadership", Journal of occupational and organizational psychology, Vol. 72 No. 4, pp. 441-462.

Beijerse, R. P. u. (2000), "Knowledge management in small and medium - sized companies: knowledge management for entrepreneurs", Journal of Knowledge Management, Vol. 4 No. 2, pp. 162-179.

Birkinshaw, J., Morrison, A. and Hulland, J. (1995), "Structural and competitive determinants of a global integration strategy", Strategic Management Journal, Vol. 16 No. 8, pp. 637-655.

Chan, I. and Chao, C.-K. (2008), "Knowledge management in small and medium-sized enterprises", Communications of the ACM, Vol. 51 No. 4, pp. 83-88.

Chen, C.-J., Huang, J.-W. and Hsiao, Y.-C. (2010), "Knowledge management and innovativeness: The role of organizational climate and structure", International Journal of Manpower, Vol. 31 No. 8, pp. 848-870.

Chin, W. W. and Newsted, P. R. (1999), "Structural equation modeling analysis with small samples using partial least squares", in Hoyle, R. (Ed.) Statistical Strategies for Small Sample Research, Sage Publications, Thousand Oaks, CA, pp. 307-341.

Cohen, J. (2013), Statistical power analysis for the behavioral sciences, Academic press.

Crawford, C. and Strohkirch, C. S. (2002), "Leadership Education for knowledge organizations: A Primer", Journal of Leadership Education, Vol. 1 No. 2, pp. 18-33.

Crawford, C. B. (2005), "Effects of transformational leadership and organizational position on knowledge management", Journal of knowledge Management, Vol. 9 No. 6, pp. 6-16.

Daugherty, P. J., Chen, H. and Ferrin, B. G. (2011), "Organizational structure and logistics service innovation", The International Journal of Logistics Management, Vol. 22 No. 1, pp. 26-51.

Dillman, D. A., Smyth, J. D. and Christian, L. M. (2014), Internet, phone, mail, and mixed-mode surveys: the tailored design method, John Wiley \& Sons, Hoboken, New Jersey.

Dotsika, F. and Keith, P. (2013), "Collaborative KM for SMEs: a framework evaluation study", Information Technology \& People, Vol. 26 No. 4, pp. 368-382.

Dwivedi, Y. K., Venkitachalam, K., Sharif, A. M., Al-Karaghouli, W. and Weerakkody, V. (2011), "Research trends in knowledge management: Analyzing the past and predicting the future", Information Systems Management, Vol. 28 No. 1, pp. 43-56.

Economic Planning Unit (2010), "10 th Malaysia Plan, 2011-2015", Putrajaya (Malaysia): Economic Planning Unit, Prime Minister's Department.

Fernandes, V. (2012), "(Re)Discovering the PLS Approach in Management Science", Management, Vol. 15 No. 1, pp. 101-123.

Geisser, S. (1974), "A predictive approach to the random effect model", Biometrika, Vol. 61 No. 1, pp. 101-107.

Goodheu, D. L., W. Lewis, and R. Thompson (2012), "Does PLS Have Advantages for Small Sample Size or Non-Normal Data?", MIS Quarterly, Vol. 36 No. 3, pp. 981-1001. 
Gregory, B. T., Harris, S. G., Armenakis, A. A. and Shook, C. L. (2009), "Organizational culture and effectiveness: A study of values, attitudes, and organizational outcomes", Journal of Business Research, Vol. 62 No. 7, pp. 673-679.

Hair, J. F., Henseler, J., Dijkstra, T., Sarstedt, M., Ringle, C., Diamantopoulos, A., Straub, D., Ketchen, D., GTM, H. and Calantone, R. (2014), "Common Beliefs and Reality about Partial Least Squares: Comments on Rönkkö and Evermann", Organizational Research Methods, Vol. 17 No. 2, pp. 182-209.

Hair, J. F., Hult, G. T. M., Ringle, C. and Sarstedt, M. (2013a), A primer on partial least squares structural equation modeling (PLS-SEM), Sage Publications Ltd., London, UK.

Hair, J. F., Ringle, C. M. and Sarstedt, M. (2011), "PLS-SEM: Indeed a silver bullet", Journal of Marketing Theory and Practice, Vol. 19 No. 2, pp. 139-152.

Hair, J. F., Ringle, C. M. and Sarstedt, M. (2013b), "Editorial-partial least squares structural equation modeling: Rigorous applications, better results and higher acceptance", Long Range Planning, Vol. 46 No. 1-2, pp. 1-12.

Henseler, J. (2010), "On the convergence of the partial least squares path modeling algorithm", Computational Statistics, Vol. 25 No. 1, pp. 107-120.

Hogan, S. J. and Coote, L. V. (2014), "Organizational culture, innovation, and performance: A test of Schein's model", Journal of Business Research, Vol. 67 No. 8, pp. 1609-1621.

Hoon Song, J., Kolb, J. A., Hee Lee, U. and Kyoung Kim, H. (2012), "Role of transformational leadership in effective organizational knowledge creation practices: Mediating effects of employees' work engagement", Human Resource Development Quarterly, Vol. 23 No. 1, pp. 65-101.

Hu, L.-t. and Bentler, P. M. (1998), "Fit indices in covariance structure modeling: Sensitivity to underparameterized model misspecification", Psychological methods, Vol. 3 No. 4, pp. 424-453.

Jafari, M., Akhavan, P. and Nourizadeh, M. (2013), "Classification of human resources based on measurement of tacit knowledge: An empirical study in Iran", Journal of Management Development, Vol. 32 No. 4, pp. 376-403.

Janet, W. C. N. and Alton, C. Y. K. (2013), "The peculiarities of knowledge management processes in SMEs: the case of Singapore", Journal of Knowledge Management, Vol. 17 No. 6, pp. 958-972.

Koellinger, P. (2008), "The relationship between technology, innovation, and firm performanceEmpirical evidence from e-business in Europe", Research policy, Vol. 37 No. 8, pp. 1317-1328.

Lee, C. S. and Wong, K. Y. (2015), "Development and validation of knowledge management performance measurement constructs for small and medium enterprises", Journal of Knowledge Management, Vol. 19 No. 4, pp. 711-734.

Lee, H. and Choi, B. (2003), "Knowledge management enablers, processes, and organizational performance: An integrative view and empirical examination", Journal of management information systems, Vol. 20 No. 1, pp. 179-228.

Lee, M. R. and Lan, Y.-C. (2011), "Toward a unified knowledge management model for SMEs", Expert Systems with Applications, Vol. 38 No. 1, pp. 729-735.

Lemon, M. and Sahota, P. S. (2004), "Organizational culture as a knowledge repository for increased innovative capacity", Technovation, Vol. 24 No. 6, pp. 483-498.

Lohmöller, J.-B. (1989), Latent variable path modeling with partial least squares, Physica-Verlag Heidelberg.

Martín-de Castro, G., López-Sáez, P., Delgado-Verde, M., Donate, M. J. and Guadamillas, F. (2011), "Organizational factors to support knowledge management and innovation", Journal of Knowledge Management, Vol. 15 No. 6, pp. 890-914.

Migdadi, M. (2009), "Knowledge management enablers and outcomes in the small - and - medium sized enterprises", Industrial Management \& Data Systems, Vol. 109 No. 6, pp. 840-858.

Nguyen, H. N. and Mohamed, S. (2011), "Leadership behaviors, organizational culture and knowledge management practices: An empirical investigation", The Journal of Management Development, Vol. 30 No. 2, pp. 206-221. 
Nonaka, I., Von Krogh, G. and Voelpel, S. (2006), "Organizational knowledge creation theory: Evolutionary paths and future advances", Organization studies, Vol. 27 No. 8, pp. 1179-1208.

Podsakoff, P. M., MacKenzie, S. B., Moorman, R. H. and Fetter, R. (1990), "Transformational leader behaviors and their effects on followers' trust in leader, satisfaction, and organizational citizenship behaviors", The Leadership Quarterly, Vol. 1 No. 2, pp. 107-142.

Politis, J. D. (2001), "The relationship of various leadership styles to knowledge management", Leadership \& Organization Development Journal, Vol. 22 No. 8, pp. 354-364.

Politis, J. D. (2002), "Transformational and transactional leadership enabling (disabling) knowledge acquisition of self - managed teams: the consequences for performance", Leadership \& Organization Development Journal, Vol. 23 No. 4, pp. 186-197.

Reinartz, W., Haenlein, M. and Henseler, J. (2009), "An empirical comparison of the efficacy of covariance-based and variance-based SEM", International Journal of research in Marketing, Vol. 26 No. 4, pp. 332-344.

Rezaei, S., Shahijan, M. K., Valaei, N., Rahimi, R. and Ismail, W. K. W. (2016), "Experienced international business traveller's behaviour in Iran: A partial least squares path modelling analysis", Tourism and Hospitality Research.

Ringle, C. M. and Sarstedt, M. (2016), "Gain more insight from your PLS-SEM results: the importanceperformance map analysis", Industrial Management \& Data Systems, Vol. 116 No. 9, pp. 1-37.

Ringle, C. M., Sarstedt, M. and Straub, D. (2012), "A critical look at the use of PLS-SEM in MIS Quarterly", MIS Quarterly (MISQ), Vol. 36 No. 1.

Sekaran, U. and Bougie, R. (2010), "Research methods for business: A skill building approach. Wiley", London.

Soper, D. (2015), "A-priori sample size calculator for Structural Equation Models [Software]".

Stone, M. (1974), "Cross-validatory choice and assessment of statistical predictions", Journal of the Royal Statistical Society. Series B (Methodological), Vol. 36 No. 2, pp. 111-147.

Teo, T. S., Srivastava, S. C. and Jiang, L. (2008), "Trust and electronic government success: An empirical study", Journal of Management Information Systems, Vol. 25 No. 3, pp. 99-132.

Valaei, N., Mohamed, N. and Karim, N. S. A. (2013), "A Conceptual Framework of Antecedents and Impacts of Knowledge Quality on SMEs' Competitiveness", in Neck, R. (Ed.) Mathematics and Computers in Contemporary Science, World Scientific and Engineering Academy and Society, Nanjing, China, pp. 187-194.

Valaei, N. and Rezaei, S. (2016), "Does Web 2.0 utilisation lead to knowledge quality, improvisational creativity, compositional creativity, and innovation in small and medium-sized enterprises? A sense-making perspective", Technology Analysis \& Strategic Management, pp. 1-14.

Valaei, N., Rezaei, S. and Ismail, W. K. W. (2016), "Examining learning strategies, creativity, and innovation at SMEs using fuzzy set Qualitative Comparative Analysis and PLS path modeling", Journal of Business Research.

von Krogh, G. (2012), "How does social software change knowledge management? Toward a strategic research agenda", The Journal of Strategic Information Systems, Vol. 21 No. 2, pp. 154-164.

Watt, S., Simpson, C., McKillop, C. and Nunn, V. (2002), "Electronic course surveys: does automating feedback and reporting give better results?", Assessment \& Evaluation in Higher Education, Vol. 27 No. 4, pp. 325-337.

Westland, J. C. (2010), "Lower bounds on sample size in structural equation modeling", Electronic Commerce Research and Applications, Vol. 9 No. 6, pp. 476-487.

Willem, A. and Buelens, M. (2009), "Knowledge sharing in inter-unit cooperative episodes: The impact of organizational structure dimensions", International Journal of Information Management, Vol. 29 No. 2, pp. 151-160.

Wold, H. (1975), "Soft modeling by latent variables: the nonlinear iterative partial least squares approach", in Gani, J. (Ed.) Perspectives in probability and statistics, papers in honour of MS Bartlett, Academic Press, London, UK, pp. 520-540. 
Wong, K. Y. (2005), "Critical success factors for implementing knowledge management in small and medium enterprises", Industrial Management \& Data Systems, Vol. 105 No. 3, pp. 261-279.

Zheng, W., Yang, B. and McLean, G. N. (2010), "Linking organizational culture, structure, strategy, and organizational effectiveness: Mediating role of knowledge management", Journal of Business Research, Vol. 63 No. 7, pp. 763-771. 
Figure 1: Theoretical framework

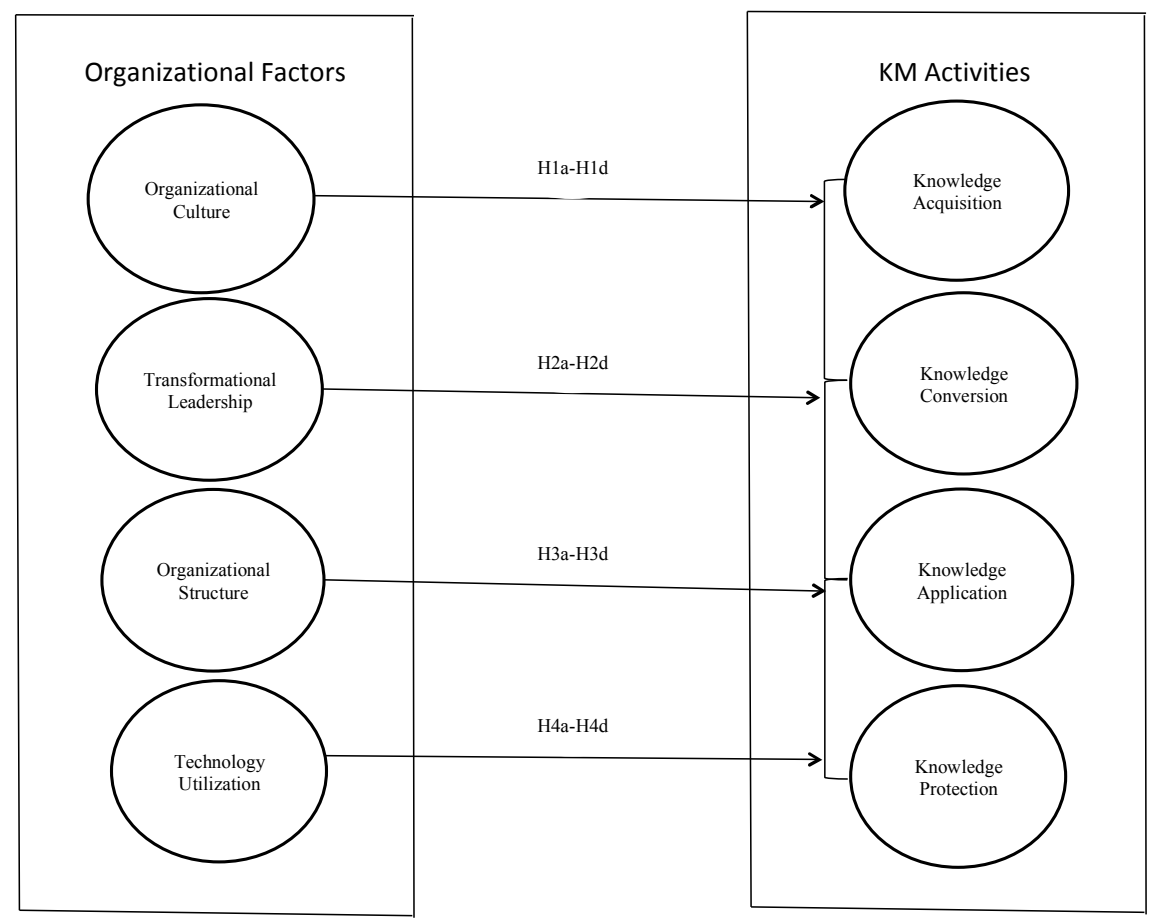

Appendix B: PLS results

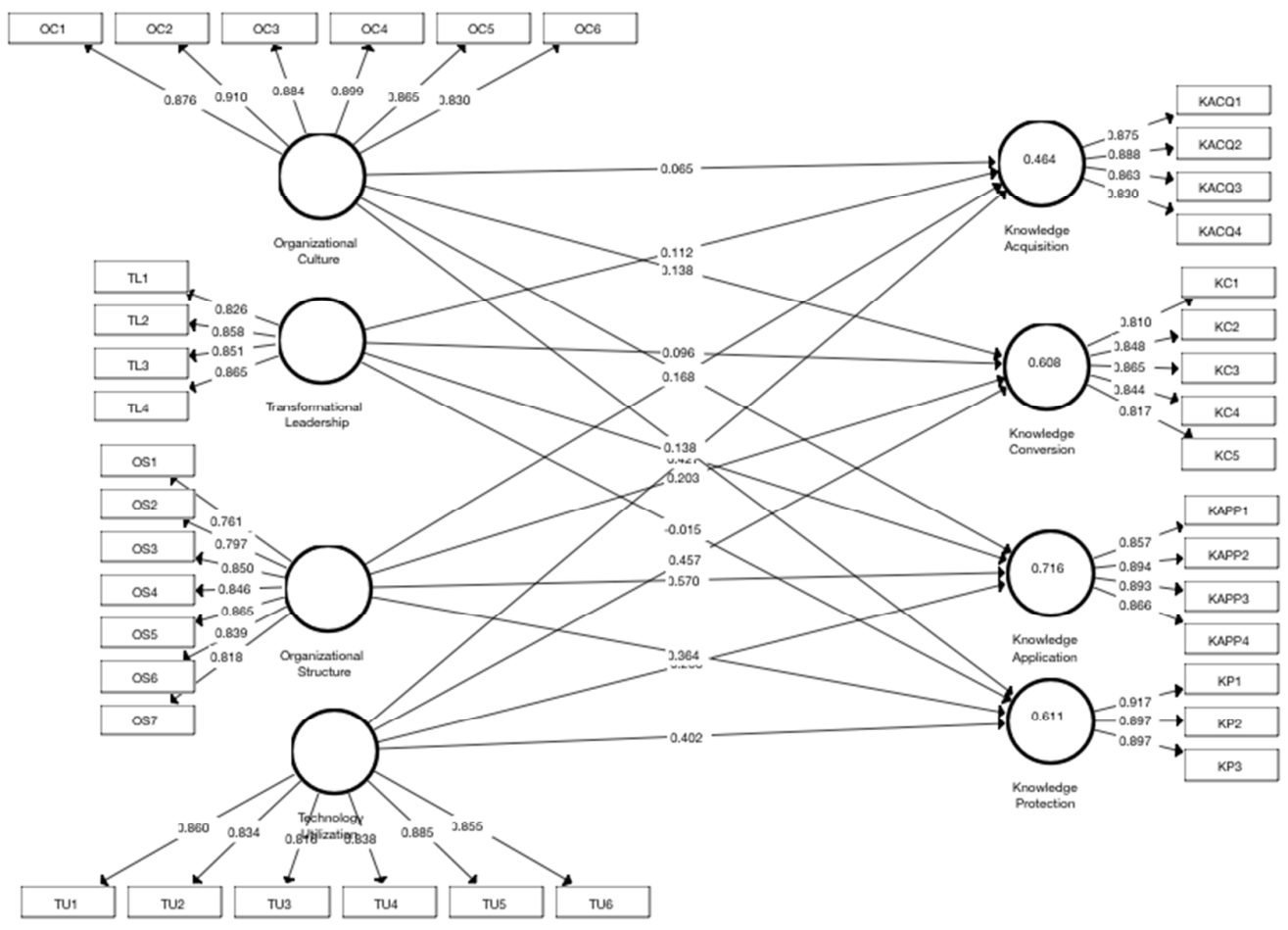


Appendix C: IPMA for Knowledge Acquisition

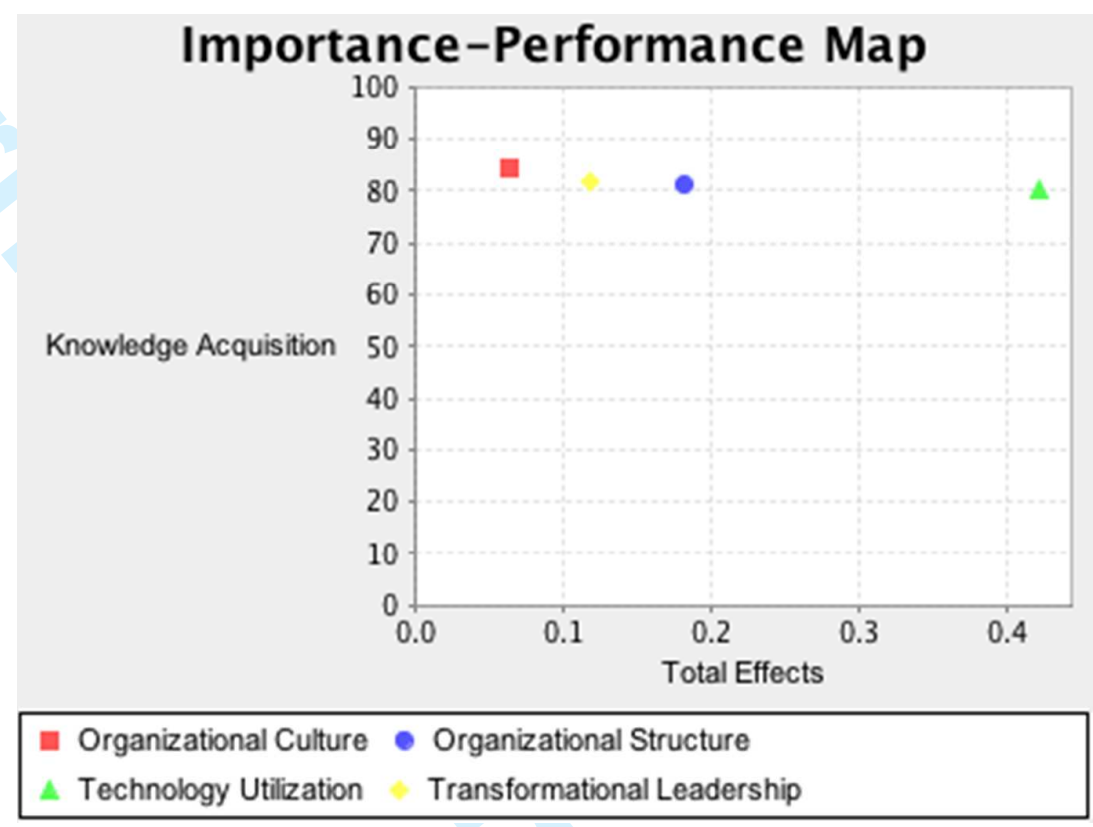

Appendix D: IPMA for Knowledge Conversion

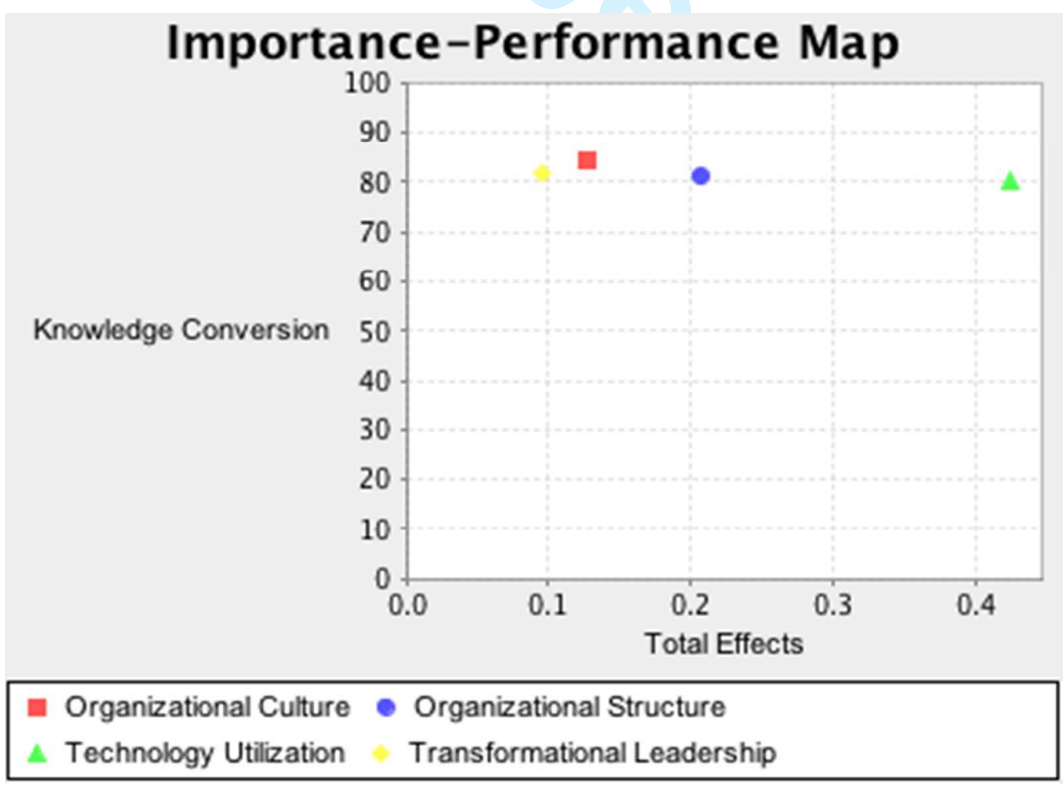


Appendix E: IPMA for Knowledge Application

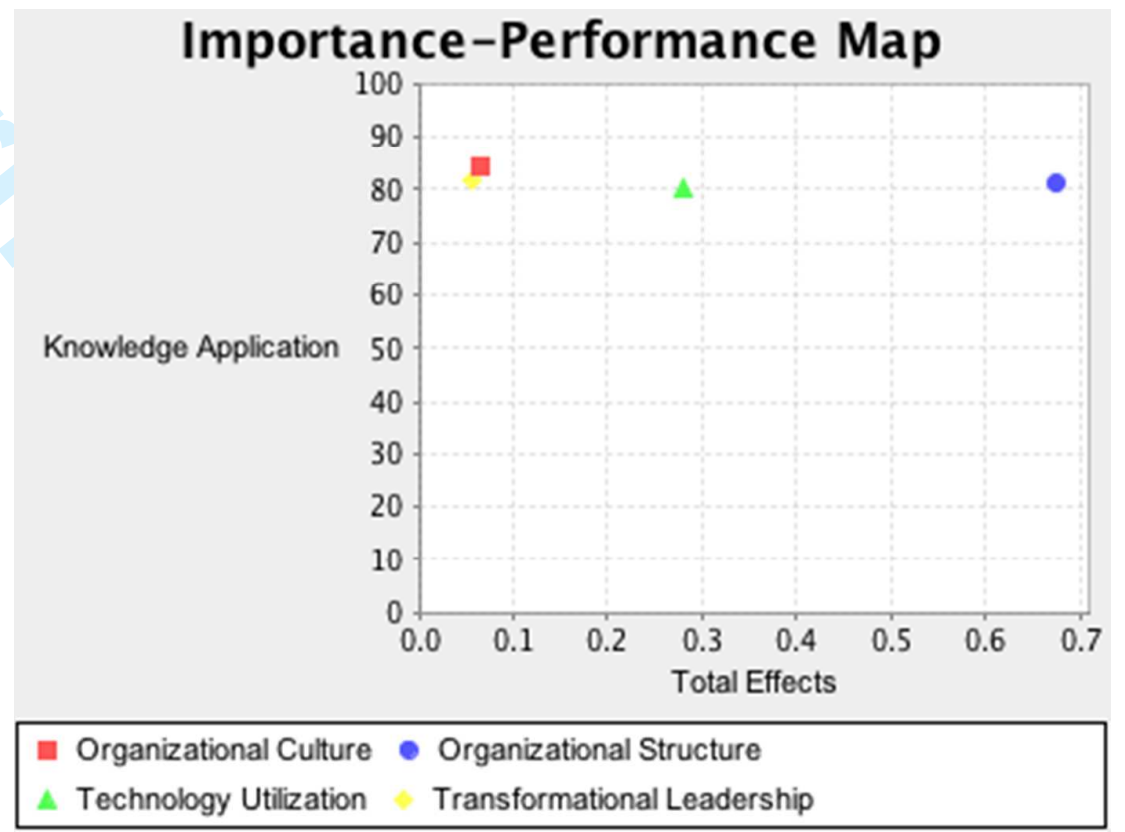

Appendix F: IPMA for Knowledge Protection

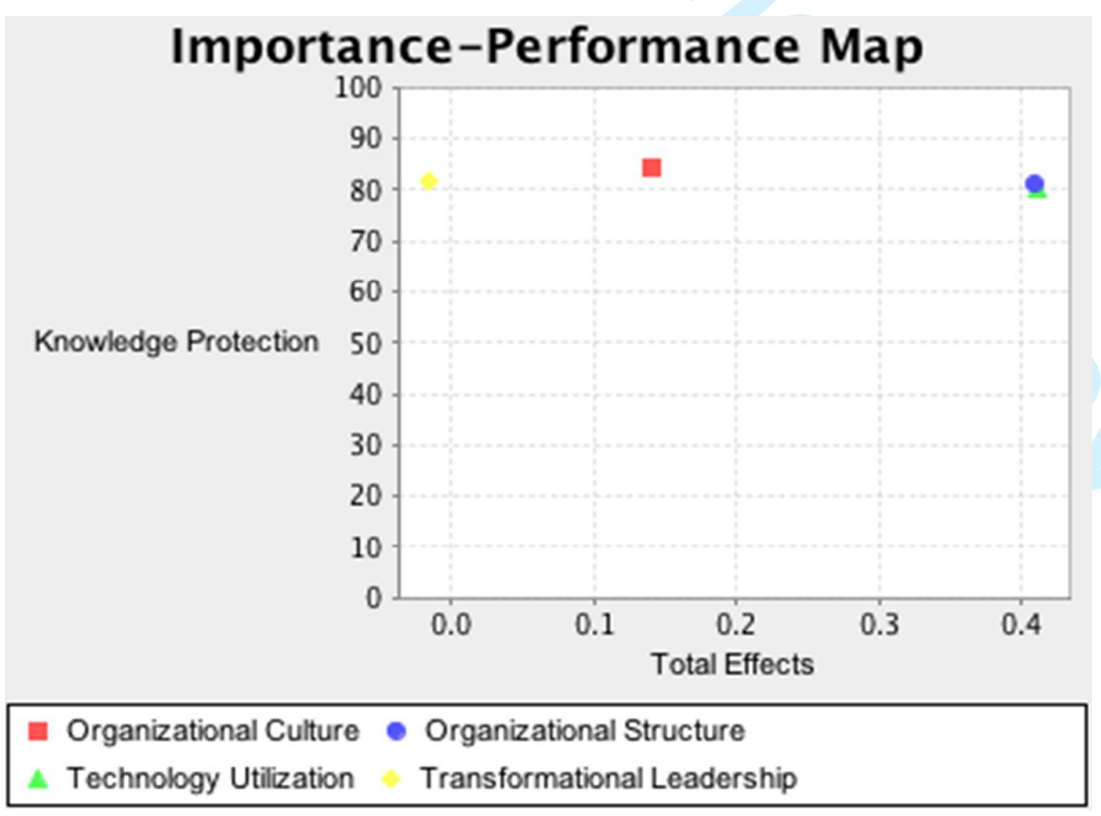


1

2

3

4

5

6

7

8

9

10

11

12

13

14

15

16

17

18

19

20

21

22

23

24

25

26

27

28

29

30

31

32

33

34

35

36

37

38

39

40

41

42

43

44

45

46

47

48

49

50

51

52

53

54

55

56

57

58

59

60

Table 1: Sample characteristics $(N=227)$

\begin{tabular}{|c|c|c|c|}
\hline & Characteristic & Frequency & Percent \\
\hline \multirow[t]{2}{*}{ Gender } & Male & 180 & 79.3 \\
\hline & Female & 47 & 20.7 \\
\hline \multirow[t]{4}{*}{ Age } & Between 20 and 30 & 71 & 31.3 \\
\hline & Between 31 and 40 & 74 & 32.6 \\
\hline & Between 41 and 50 & 64 & 28.2 \\
\hline & Between 51 and 60 & 18 & 7.9 \\
\hline \multirow[t]{6}{*}{ Position } & CEO & 112 & 49.3 \\
\hline & $\mathrm{CFO}$ & 11 & 4.8 \\
\hline & $\mathrm{COO}$ & 10 & 4.4 \\
\hline & $\mathrm{CIO}$ & 13 & 5.7 \\
\hline & $\mathrm{CMO}$ & 19 & 8.4 \\
\hline & Manager & 62 & 27.3 \\
\hline \multirow[t]{4}{*}{ Number of Employees } & Between 10 and 30 & 83 & 36.6 \\
\hline & Between 31 and 50 & 68 & 30 \\
\hline & Between 51 and 70 & 50 & 22 \\
\hline & Between 71 and 100 & 26 & 11.5 \\
\hline
\end{tabular}


Table 2: Construct reliability and validity

\begin{tabular}{|c|c|c|c|c|c|c|}
\hline Construct & Item & $\begin{array}{c}\text { Item } \\
\text { loading }\end{array}$ & $\mathbf{V I F}^{\mathrm{a}}$ & $\mathbf{A V E}^{\mathbf{b}}$ & $\begin{array}{l}\text { Composite } \\
\text { Reliability }^{c}\end{array}$ & $\begin{array}{c}\text { Cronbach's } \\
\text { Alpha }\end{array}$ \\
\hline \multirow[t]{4}{*}{ Knowledge Acquisition } & KACQ1 & 0.875 & 2.617 & 0.747 & 0.922 & 0.887 \\
\hline & KACQ2 & 0.888 & 2.687 & & & \\
\hline & KACQ3 & 0.863 & 2.399 & & & \\
\hline & KACQ4 & 0.830 & 2.065 & & & \\
\hline \multirow[t]{5}{*}{ Knowledge Conversion } & $\mathrm{KC} 1$ & 0.810 & 2.523 & 0.700 & 0.921 & 0.893 \\
\hline & $\mathrm{KC} 2$ & 0.848 & 2.893 & & & \\
\hline & $\mathrm{KC} 3$ & 0.865 & 2.548 & & & \\
\hline & $\mathrm{KC4}$ & 0.844 & 2.760 & & & \\
\hline & $\mathrm{KC} 5$ & 0.817 & 2.534 & & & \\
\hline \multirow[t]{4}{*}{ Knowledge Application } & KAPP1 & 0.857 & 2.372 & 0.770 & 0.931 & 0.900 \\
\hline & KAPP2 & 0.894 & 2.853 & & & \\
\hline & KAPP3 & 0.893 & 2.866 & & & \\
\hline & KAPP4 & 0.866 & 2.594 & & & \\
\hline \multirow[t]{3}{*}{ Knowledge Protection } & KP1 & 0.917 & 2.838 & 0.817 & 0.930 & 0.888 \\
\hline & KP2 & 0.897 & 2.456 & & & \\
\hline & KP3 & 0.897 & 2.478 & & & \\
\hline \multirow[t]{6}{*}{ Organizational Culture } & OC1 & 0.876 & 3.583 & 0.770 & 0.953 & 0.940 \\
\hline & $\mathrm{OC} 2$ & 0.910 & 4.930 & & & \\
\hline & OC3 & 0.884 & 3.989 & & & \\
\hline & OC4 & 0.899 & 4.439 & & & \\
\hline & OC5 & 0.865 & 3.370 & & & \\
\hline & OC6 & 0.830 & 2.764 & & & \\
\hline \multirow[t]{7}{*}{ Organizational Structure } & OS1 & 0.761 & 2.189 & 0.682 & 0.937 & 0.922 \\
\hline & OS2 & 0.797 & 2.910 & & & \\
\hline & OS3 & 0.850 & 3.119 & & & \\
\hline & OS4 & 0.846 & 2.963 & & & \\
\hline & OS5 & 0.865 & 3.283 & & & \\
\hline & OS6 & 0.839 & 3.237 & & & \\
\hline & OS7 & 0.818 & 2.760 & & & \\
\hline \multirow[t]{4}{*}{ Technology Utilization } & TU1 & 0.860 & 3.021 & 0.719 & 0.939 & 0.922 \\
\hline & TU2 & 0.834 & 2.998 & & & \\
\hline & TU3 & 0.816 & 3.043 & & & \\
\hline & TU4 & 0.838 & 3.058 & & & \\
\hline
\end{tabular}


Table 3: Discriminant validity - Fornell-Larcker criterion

\begin{tabular}{lcccccccc}
\hline & KAcq & KApp & KC & KP & OC & OS & TU & TL \\
\hline Knowledge Acquisition & $\mathbf{0 . 8 6 4}$ & & & & & & & \\
Knowledge Application & 0.527 & $\mathbf{0 . 8 7 8}$ & & & & & & \\
Knowledge Conversion & 0.723 & 0.656 & $\mathbf{0 . 8 3 7}$ & & & & & \\
Knowledge Protection & 0.516 & 0.792 & 0.629 & $\mathbf{0 . 9 0 4}$ & & & & \\
Organizational Culture & 0.468 & 0.554 & 0.567 & 0.548 & $\mathbf{0 . 8 7 8}$ & & & \\
Organizational Structure & 0.577 & 0.816 & 0.663 & 0.705 & 0.558 & $\mathbf{0 . 8 2 6}$ & & \\
Technology Utilization & 0.646 & 0.711 & 0.731 & 0.716 & 0.538 & 0.682 & $\mathbf{0 . 8 4 8}$ & \\
Transformational Leadership & 0.552 & 0.677 & 0.634 & 0.608 & 0.721 & 0.738 & 0.632 & $\mathbf{0 . 8 5 0}$ \\
\hline
\end{tabular}

a. Variance Inflation Factor

b. Average variance extracted $(\mathrm{AVE})=($ summation of the square of the factor loadings $) /[$ (summation of the square of the factor loadings $)+$ (summation of the error variances)]

c. Composite reliability $(\mathrm{CR})=$ (square of the summation of the factor loadings) $/[$ (square of the summation of the factor loadings) + (square of the summation of the error variances)]

a. The off-diagonal values in the above matrix are the correlations between the latent constructs and diagonal are square values of AVEs.

Note: KAcq (Knowledge Acquisition), KApp (Knowledge Application), KC (Knowledge Conversion), KP (Knowledge Protection), OC (Organizational Culture), OS (Organizational Structure), TU (Technology Utilization), TL (Transformational Leadership).

Table 4: Discriminant validity - Heterotrait-Monotrait Ratio

\begin{tabular}{|c|c|c|c|c|c|c|c|}
\hline Construct & $\begin{array}{l}\text { Knowledge } \\
\text { Acquisition }\end{array}$ & $\begin{array}{l}\text { Knowledge } \\
\text { Application }\end{array}$ & $\begin{array}{l}\text { Knowledge } \\
\text { Conversion }\end{array}$ & $\begin{array}{l}\text { Knowledge } \\
\text { Protection }\end{array}$ & $\begin{array}{l}\text { Organizational } \\
\text { Culture }\end{array}$ & $\begin{array}{l}\text { Organizational } \\
\text { Structure }\end{array}$ & $\begin{array}{l}\text { Technology } \\
\text { Utilization }\end{array}$ \\
\hline Knowledge & & & & & & & \\
\hline Application & $0.590^{\mathrm{a}}$ & & & & & & \\
\hline Knowledge & & & & & & & \\
\hline Conversion & 0.809 & 0.727 & & & & & \\
\hline Knowledge & & & & & & & \\
\hline Protection & 0.580 & 0.887 & 0.705 & & & & \\
\hline Organizational & & & & & & & \\
\hline Culture & 0.510 & 0.600 & 0.616 & 0.597 & & & \\
\hline Organizational & & & & & & & \\
\hline Structure & 0.636 & 0.895 & 0.726 & 0.778 & 0.600 & & \\
\hline Technology & & & & & & & \\
\hline Utilization & 0.714 & 0.780 & 0.803 & 0.789 & 0.578 & 0.738 & \\
\hline Transformational & & & & & & & \\
\hline Leadership & 0.624 & 0.761 & 0.715 & 0.688 & 0.795 & 0.825 & 0.701 \\
\hline
\end{tabular}


Table 5: Structural relationships and hypothesis testing

\begin{tabular}{|c|c|c|c|c|c|}
\hline Hypothesis & Path & Beta & $\begin{array}{c}\text { Standard } \\
\text { Error }\end{array}$ & $\begin{array}{c}\text { T- } \\
\text { Statistics }\end{array}$ & Decision \\
\hline H1a & Organizational Culture -> Knowledge Acquisition & 0.065 & 0.074 & 0.878 & Not Supported \\
\hline $\mathrm{H} 1 \mathrm{~b}$ & Organizational Culture -> Knowledge Conversion & 0.138 & 0.063 & $2.202 * *$ & Supported \\
\hline $\mathrm{H} 1 \mathrm{c}$ & Organizational Culture -> Knowledge Application & 0.061 & 0.064 & 0.951 & Not Supported \\
\hline H1d & Organizational Culture $->$ Knowledge Protection & 0.138 & 0.081 & $1.709 *$ & Supported \\
\hline $\mathrm{H} 2 \mathrm{a}$ & Transformational Leadership -> Knowledge Acquisition & 0.112 & 0.065 & $1.723 *$ & Supported \\
\hline $\mathrm{H} 2 \mathrm{~b}$ & Transformational Leadership -> Knowledge Conversion & 0.096 & 0.085 & 1.128 & Not Supported \\
\hline $\mathrm{H} 2 \mathrm{c}$ & Transformational Leadership -> Knowledge Application & 0.048 & 0.101 & 0.472 & Not Supported \\
\hline $\mathrm{H} 2 \mathrm{~d}$ & Transformational Leadership -> Knowledge Protection & -0.015 & 0.086 & 0.168 & Not Supported \\
\hline $\mathrm{H} 3 \mathrm{a}$ & Organizational Structure -> Knowledge Acquisition & 0.168 & 0.092 & $1.822 *$ & Supported \\
\hline $\mathrm{H} 3 \mathrm{~b}$ & Organizational Structure -> Knowledge Conversion & 0.203 & 0.101 & $2.017 * *$ & Supported \\
\hline $\mathrm{H} 3 \mathrm{c}$ & Organizational Structure $->$ Knowledge Application & 0.570 & 0.098 & $5.823 * * *$ & Supported \\
\hline $\mathrm{H} 3 \mathrm{~d}$ & Organizational Structure $->$ Knowledge Protection & 0.364 & 0.095 & $3.846^{* * *}$ & Supported \\
\hline $\mathrm{H} 4 \mathrm{a}$ & Technology Utilization -> Knowledge Acquisition & 0.427 & 0.078 & $5.500 * * *$ & Supported \\
\hline $\mathrm{H} 4 \mathrm{~b}$ & Technology Utilization -> Knowledge Conversion & 0.457 & 0.075 & $6.076 * * *$ & Supported \\
\hline $\mathrm{H} 4 \mathrm{c}$ & Technology Utilization -> Knowledge Application & 0.260 & 0.089 & $2.925 * * *$ & Supported \\
\hline $\mathrm{H} 4 \mathrm{~d}$ & Technology Utilization -> Knowledge Protection & 0.402 & 0.107 & $3.750 * * *$ & Supported \\
\hline
\end{tabular}

Table 6: IPMA Results

\begin{tabular}{ccccccccc}
\hline Construct & \multicolumn{2}{l}{ Knowledge Acquisition } & \multicolumn{2}{l}{ Knowledge Conversion } & \multicolumn{2}{l}{ Knowledge Application } & Knowledge Protection \\
\hline & Importance & Performance & Importance & Performance & Importance & Performance & Importance & Performance \\
\hline $\begin{array}{c}\text { Organizational } \\
\text { Culture }\end{array}$ & 0.064 & 84.111 & 0.128 & 84.111 & 0.066 & 84.111 & 0.141 & 84.111 \\
$\begin{array}{c}\text { Organizational } \\
\text { Structure }\end{array}$ & 0.182 & 81.126 & 0.207 & 81.126 & 0.674 & 81.126 & 0.409 & 81.126 \\
$\quad \begin{array}{c}\text { Technology } \\
\quad \text { Utilization }\end{array}$ & 0.422 & 80.163 & 0.425 & 80.163 & 0.280 & 80.163 & 0.412 & 80.163 \\
$\begin{array}{c}\text { Transformational } \\
\text { Leadership }\end{array}$ & 0.119 & 81.598 & 0.096 & 81.598 & 0.056 & 81.598 & -0.016 & 81.598 \\
\hline
\end{tabular}

Note: Importance $=$ total effects of structural model, Performance = average values of latent variable scores (Hair Jr et al., 2013). 
2

Appendix A: Measurement items

\begin{tabular}{|c|c|c|c|}
\hline & Construct & Item & Source \\
\hline 1 & $\begin{array}{l}\text { Technology } \\
\text { Utilization }\end{array}$ & $\begin{array}{l}\text { TU1 Systems are in place to locate individuals with the expertise or 'know how' that is necessary to perform my job } \\
\text { effectively. } \\
\text { TU2 The organization has IT platform in place to support knowledge sharing. } \\
\text { TU3 Communication channels are in place that allow for the sharing of knowledge between SMEs. } \\
\text { TU4 The organization has invested in effective knowledge management technologies to enable knowledge sharing } \\
\text { between employees (e.g. intranets/extranets, groupware, repositories, etc.). } \\
\text { TU5 Employees are able to acquire important work related knowledge from the Internet and other electronic } \\
\text { sources. } \\
\text { TU6 Information technology plays a critical role in facilitating knowledge sharing. }\end{array}$ & $\begin{array}{l}\text { (Lee and Lan, } \\
\text { 2011); (Chan } \\
\text { and Chao, } \\
\text { 2008); (Valaei } \\
\text { and Rezaei, } \\
\text { 2016) }\end{array}$ \\
\hline 2 & $\begin{array}{l}\text { Organizational } \\
\text { Structure }\end{array}$ & $\begin{array}{l}\text { OS1 The organization encourages knowledge sharing amongst employees. } \\
\text { OS2 The organization has processes in place to facilitate knowledge exchange and conversion across business } \\
\text { functions (e.g. organizational departments and/or divisions). } \\
\text { OS3 The organizational structure promotes collaborative rather than individualistic working behaviour. } \\
\text { OS4 The organizational structure facilitates knowledge discovery and creation. } \\
\text { OS5 The organization possesses the system to collect various successful and failed experiences. } \\
\text { OS6 The organization has a high "Reuse Rate" of important knowledge. } \\
\text { OS7 The organization has a common knowledge platform to enable employees to seek for work-related assistance. }\end{array}$ & $\begin{array}{l}\text { (Lee and Lan, } \\
\text { 2011); (Chan } \\
\text { and Chao, 2008) }\end{array}$ \\
\hline 3 & $\begin{array}{l}\text { Organizational } \\
\text { Culture }\end{array}$ & $\begin{array}{l}\text { OC1 Employees realize the importance of knowledge asset to the organization success. } \\
\text { OC2 Employees have high level of trusts in knowledge sharing. } \\
\text { OC3 The organization support sufficient resources and trainings to increase employees' work efficiency. } \\
\text { OC4 Employees are encouraged to seek for work related knowledge. } \\
\text { OC5 Overall organizational vision and objectives are clearly stated. } \\
\text { OC6 The organization understands that the benefits of sharing knowledge outweigh the costs. }\end{array}$ & $\begin{array}{l}\text { (Lee and Lan, } \\
\text { 2011); (Chan } \\
\text { and Chao, 2008) }\end{array}$ \\
\hline 4 & $\begin{array}{l}\text { Transformational } \\
\text { Leadership }\end{array}$ & $\begin{array}{l}\text { TL1 Top management seeks different views. } \\
\text { TL2 Top management considers the moral/ethical standards. } \\
\text { TL3 Top management suggests new ways. } \\
\text { TL4 Top management talks enthusiastically. } \\
\text { TL5 Top management emphasizes the collective mission of the company. } \\
\text { TL6 Top management teaches and coaches. }\end{array}$ & $\begin{array}{l}\text { (Avolio et al., } \\
\text { 1999) }\end{array}$ \\
\hline 5 & $\begin{array}{l}\text { Knowledge } \\
\text { Acquisition }\end{array}$ & $\begin{array}{l}\text { KACQ1 The organization has the procedures to acquire supplier and customer related knowledge. } \\
\text { KACQ2 The organization has the procedures to create new knowledge from exiting knowledge. } \\
\text { KACQ3 The organization has the procedures to acquire and exchange knowledge between employees. } \\
\text { KACQ4 The organization has the procedures to acquire new product/service and competitor related knowledge } \\
\text { within the same industry sector. }\end{array}$ & $\begin{array}{l}\text { (Lee and Lan, } \\
\text { 2011); (Chan } \\
\text { and Chao, 2008) }\end{array}$ \\
\hline 6 & $\begin{array}{l}\text { Knowledge } \\
\text { Conversion }\end{array}$ & $\begin{array}{l}\text { KC1 The organization has the procedures to convert knowledge to new products or designs. } \\
\text { KC2 The organization has the procedures to convert competitive intelligence to operational plan. } \\
\text { KC3 The organization has the procedures to promote the operational knowledge and transfer it to employees. } \\
\text { KC4 The organization has the procedures to transform knowledge from employees and business partners to its } \\
\text { operations. }\end{array}$ & $\begin{array}{l}\text { (Lee and Lan, } \\
\text { 2011); (Chan } \\
\text { and Chao, 2008) }\end{array}$ \\
\hline 7 & $\begin{array}{l}\text { Knowledge } \\
\text { Application }\end{array}$ & $\begin{array}{l}\text { KAPP1 The organization has the capability to exploit knowledge gained from the failures and experiences. } \\
\text { KAPP2 The organization has the capability to utilize knowledge for solving new problems. } \\
\text { KAPP3 The organization is able to utilize knowledge for improving work effectiveness and fine-tuning strategic } \\
\text { vision. } \\
\text { KAPP4 The organization can rapidly supply the necessary knowledge to appropriate parties. }\end{array}$ & $\begin{array}{l}\text { (Lee and Lan, } \\
2011) ;(\text { Chan } \\
\text { and Chao, 2008) }\end{array}$ \\
\hline 8 & $\begin{array}{l}\text { Knowledge } \\
\text { Protection }\end{array}$ & $\begin{array}{l}\text { KP1 The organization has the procedures to protect organizational knowledge and assure it is not accessed } \\
\text { unauthentically. } \\
\text { KP2 The organization has login and access policies to protect organizational knowledge. } \\
\text { KP3 The organization has clear information to employees with regard to the importance of knowledge protection. }\end{array}$ & $\begin{array}{l}\text { (Lee and Lan, } \\
\text { 2011); (Chan } \\
\text { and Chao, 2008) }\end{array}$ \\
\hline
\end{tabular}

